\title{
On the Solubility of Quercetin
}

Michael H Abraham, ${ }^{\text {a }}$ William E. Acree, $\mathrm{Jr}^{b}$

${ }^{a}$ Department of Chemistry, University College London, 20 Gordon St, London WC1H 0AJ, UK.

${ }^{b}$ Department of Chemistry, 1155 Union Circle Drive \#305070, University of North Texas, Denton, TX 76203-5017, USA

\begin{abstract}
There is considerable disagreement over the solubility of quercetin in water. Experimental values of $\log C w$ with $C w$ in mol/L range from -2.52 to -5.89 , a difference of over three $\log$ units. We have applied a methodology based on linear free energy equations for water-solvent and gassolvent partitions to study solubilities. These are related to partition coefficients through $P s=$ $C s / C w$ where $C s$ and $C w$ are solubilities of a given solute in a solvent and in water. We find that known solubilities of quercetin in methanol and ethanol at $298 \mathrm{~K}$ and a known water-solvent partition coefficient can be accommodated in the same model if the water solubility at $298 \mathrm{~K}$, as $\log C w$, is taken as -3.90 , that is near to the middle of the range of experimental values. Our model successfully predicts solubilities of quercetin in water-ethanol mixtures near to the ethanol rich mixtures.
\end{abstract}

Keywords:

Quercetin

Water-solvent partition coefficient

Gas-water partition coefficient

Solubility

Linear Free Energy Relationships

Abraham descriptors

* Corresponding author.

E-mail address: m.h.abraham@ucl.ac.uk (M. H. Abraham)

E-mail address: Bill.Acree@unt.edu (W. E. Acree, Jr) 


\section{Introduction}

It is known that quercetin $\left(3,5,7,3^{\prime}, 4^{\prime}\right.$-pentahydroxyflavone) is very sparingly soluble in water, but determinations of the actual solubility yield very varied results. Althans et al. [1] have recently summarized the various measurements that have been made, and in Table 2 we list recorded solubilities in water at $298 \mathrm{~K}$, as $\log C w$ in units of mol/L. Although these determinations vary by more than three log units, it seems almost impossible to make a selection, especially given the very low solubility and the consequent experimental difficulty of the measurements. On numerous occasions, we have studied the solubility of a given compound in nonaqueous solvents, and have shown that it is possible to obtain an indirect estimate of the solubility in water. It seemed of interest to apply this indirect method to the solubility of quercetin and so provide another route altogether for the estimation of the solubility in water.

\section{Table 1}

Recorded solubilities of quercetin in water at $298 \mathrm{~K}$, as $\log C w$

\begin{tabular}{|l|l|}
\hline $\log C w(\mathrm{~mol} / \mathrm{L})$ & Ref \\
\hline-2.52 & {$[2]$} \\
\hline-3.70 & {$[3]$} \\
\hline-4.30 & {$[4]$} \\
\hline$-4.52(323 \mathrm{~K})$ & {$[5]$} \\
\hline-4.59 & {$[6]$} \\
\hline-5.89 & {$[1]$} \\
\hline
\end{tabular}

\section{Methodology}

Our method is based on two linear free energy equations, Eq. (1) and Eq. (2). The dependent variable, SP, consists of a series of values of some physicochemical property of a series of solutes in a given solvent system. In the present work, $S P$ in Eq. (1) can be a watersolvent partition, as $\log P$, of a series of solutes in a given water-solvent, and $S P$ in Eq.(2) can be a gas-solvent partition, as $\log K$, of a series of solutes in a given gas-solvent system.

$$
\begin{aligned}
& S P=c+e \mathbf{E}+s \mathbf{S}+a \mathbf{A}+b \mathbf{B}+v \mathbf{V} \\
& S P=c+e \mathbf{E}+s \mathbf{S}+a \mathbf{A}+b \mathbf{B}+l \mathbf{L}
\end{aligned}
$$


The independent variables, or descriptors, in Eq. (1) and Eq. (2) are properties of solutes as follows [7-9] : $\mathbf{E}$ is an excess molar refraction in $\mathrm{cm}^{3} \mathrm{~mol}^{-1} / 10, \mathbf{S}$ is a combined dipolarity/ polarizability descriptor, $\mathbf{A}$ is the overall solute hydrogen bond acidity, $\mathbf{B}$ is the overall solute hydrogen bond basicity, $\mathbf{V}$ is McGowan's characteristic molecular volume in $\mathrm{cm}^{3} \mathrm{~mol}^{-1} / 100$ and $\mathbf{L}$ is the logarithm of the gas to hexadecane partition coefficient at $298 \mathrm{~K}$. The set of coefficients, $c, e, s, a, b, v$ and $l$ characterise the system and are determined by multiple linear regression analysis. The descriptors in Eq. (1) and Eq. (2) are obtained from known equations for watersolvent partition coefficients, and known values of the corresponding partition coefficients for a given solute. The method has been described in considerable detail [8-11], especially by Clarke and Mallon [11] who give a number of specific examples.

In order to apply the method to solubilities, $C$, the latter are converted into water-solvent partition coefficients through Eq. (3), where $P s$ is a water to solvent partition coefficient, $C s$ is the molar solubility in the solvent and $C w$ is the molar solubility in water. Usually, solubilities are measured with dry solvents and so Ps in Eq. (3) will then refer to the (hypothetical) partition between water and a dry solvent.

$P s=C s / C w$

It is useful to introduce another descriptor, $K w$, the gas to water partition coefficient (no units) so that all values of $P s$ can be converted into the corresponding values of $K s$, the gas to solvent partition coefficient, Eq. (4).

$K s=C s / C g \quad K s=P s . K w$

In the special case for which $C w$ in Eq. (3) is unknown, this can be used as another descriptor to be determined, and is obtained by trial and error together with the other unknown descriptors. Then we start with no less than eight descriptors that have to be determined from a set of equations, viz: E, S, A, B, V, L, Kw. and $C s$. However, $\mathbf{E}$ can be obtained either from a calculated refractive index at $293 \mathrm{~K}$ [12], or even better as a calculated value using the ACD software[13] and $\mathbf{V}$ can be calculated from structure [7]. In the present case, we are fortunate that Whaley et al. [14] have determined A-values for hydroxyflavones using an NMR method [15], 
and we can use this data to assign $\mathbf{A}=1.92$ for quercetin. Then the outstanding descriptors of quercetin to calculate are reduced to $\mathbf{S}, \mathbf{B}, \mathbf{L}, \log K w$ and $\log C w$.

\section{Results}

A value for the water-octanol partition coefficient of quercetin, $\log P($ oct $)=2.06$, is available [16], Althans et al. [1] have determined the solubility in ethanol and Razmara et al.[2] the solubility in methanol at $298 \mathrm{~K}$. Then use of $C w$ allows $\log P($ ethanol) and $\log P$ (methanol) to be deduced, and use of $K w$ allows $\log K$ values for gas to ethanol partition and gas to methanol partition to be deduced. In addition, we have equations on the lines of Eq. (1) and Eq. (2) for gas to water partitions, thus leading to eight equations from which to calculate the five required descriptors. The equations and their coefficients are in Table 2. We include also equations and coefficients for partition from water to various water-ethanol mixtures, with compositions expressed as vol \%.

\section{Table 2}

Equations and coefficients for water-solvent and gas-solvent partitions, as $\log P$ and $\log K$

\begin{tabular}{|l|c|c|c|c|c|c|c|}
\hline Solvent & $c$ & $e$ & $s$ & $a$ & $b$ & $v$ & $l$ \\
\hline Log $P$, Eq. (1). & & & & & & & \\
\hline Water - octanol, wet & 0.088 & 0.562 & -1.054 & 0.034 & -3.460 & 3.814 & 0.000 \\
\hline Water-methanol & 0.276 & 0.334 & -0.714 & 0.243 & -3.320 & 3.549 & 0.000 \\
\hline Water-ethanol & 0.222 & 0.471 & -1.035 & 0.326 & -3.596 & 3.857 & 0.000 \\
\hline Water- 96\% ethanol & 0.238 & 0.353 & -0.833 & 0.297 & -3.533 & 3.724 & 0.000 \\
\hline Water- 95\% ethanol & 0.239 & 0.328 & -0.795 & 0.294 & -3.514 & 3.697 & 0.000 \\
\hline Water- 90\% ethanol & 0.243 & 0.213 & -0.575 & 0.262 & -3.450 & 3.545 & 0.000 \\
\hline Water- 80\% ethanol & 0.172 & 0.175 & -0.465 & 0.260 & -3.212 & 3.323 & 0.000 \\
\hline Water- 70\% ethanol & 0.063 & 0.085 & -0.368 & 0.311 & -2.936 & 3.102 & 0.000 \\
\hline Water- 60\% ethanol & -0.040 & 0.138 & -0.335 & 0.293 & -2.675 & 2.812 & 0.000 \\
\hline Water- 50\% ethanol & -0.142 & 0.124 & -0.252 & 0.251 & -2.275 & 2.415 & 0.000 \\
\hline Water- 40\% ethanol & -0.221 & 0.131 & -0.159 & 0.171 & -1.809 & 1.918 & 0.000 \\
\hline Water- 30\% ethanol & -0.269 & 0.107 & -0.098 & 0.133 & -1.316 & 1.414 & 0.000 \\
\hline Water- 20\% ethanol & -0.252 & 0.042 & -0.040 & 0.096 & -0.823 & 0.916 & 0.000 \\
\hline Water- 10\% ethanol & -0.173 & -0.023 & -0.001 & 0.065 & -0.372 & 0.454 & 0.000 \\
\hline Gas - water & -0.994 & 0.577 & 2.549 & 3.813 & 4.841 & -0.869 & 0.000 \\
\hline & & & & & & & \\
\hline Log K, Eq. (2) & & & & & & & \\
\hline Gas - octanol, wet & -0.198 & 0.002 & 0.709 & 3.519 & 1.429 & 0.000 & 0.858 \\
\hline
\end{tabular}




\begin{tabular}{|l|c|c|c|c|c|c|c|}
\hline Gas-methanol & -0.039 & -0.338 & 1.317 & 3.826 & 1.396 & 0.000 & 0.773 \\
\hline Gas-ethanol & 0.017 & -0.232 & 0.867 & 3.894 & 1.192 & 0.000 & 0.846 \\
\hline Gas - water & -1.271 & 0.822 & 2.743 & 3.904 & 4.814 & 0.000 & -0.213 \\
\hline
\end{tabular}

Razmara et al. [2] also determined solubilities in a number of water-ethanol mixtures. In view of the large disparity in the solubility in water determined by Razmara et al. [2] and by Althans et al. [1] we chose not to use the these solubilities in our analysis but to predict the water-ethanol solubilities and then to compare the predictions with the experimental values. The required coefficients for partition between water and water-ethanol mixtures are in Table 2 [31]. Chebil et al. [5] have also determined solubilities in a few nonaqueous solvents, but only at 323 $\mathrm{K}$, and so we did not use these results, especially as Althans et al. [1] have shown that quercetin in water decomposes at temperatures higher than $316 \mathrm{~K}$..

Our analysis of the quercetin data is shown in Table 3. For the eight values of $\log P s$ observed and calculated, the average deviation $\mathrm{AE}=0.009$, the absolute average deviation AAE $=0.051$ and the standard deviation SD $=0.071 \log$ units, so that the fit is excellent. The obtained descriptors for quercetin are in Table 4. The deduced value of the solubility in water, as $\log C w$ at $298 \mathrm{~K}$ is -3.90 and the corresponding solubilities in methanol and ethanol are in Table 3. As shown by the example of partition into wet octanol, it is now possible to predict values of $\log P s$ for partition of quercetin into any solvent for which the coefficients in Eq. (1) are known, and then to obtain the corresponding solubilities at $298 \mathrm{~K}$. Currently equation coefficients have been reported for more than 55 different organic solvents [9].

Table 3

Analysis of the data for quercetin at $298 \mathrm{~K}$

\begin{tabular}{|l|r|r|r|r|}
\hline & \multicolumn{2}{|c|}{$\log P s$} & \multicolumn{2}{c|}{ Log $C s$} \\
\hline System & \multicolumn{1}{|c|}{ Obs } & \multicolumn{1}{c|}{ Calc } & & Calc \\
\hline Water-wet octanol & 2.06 & 1.98 & & -1.92 \\
\hline Water-methanol & 2.26 & 2.39 & -1.64 & -1.51 \\
\hline Water-ethanol & 2.37 & 2.37 & -1.53 & -1.53 \\
\hline Gas-water & 18.56 & 18.55 & & \\
\hline & & & & \\
\hline Gas-wet octanol & 20.62 & 20.71 & & \\
\hline Gas-methanol & 20.82 & 20.79 & & \\
\hline Gas-ethanol & 20.93 & 20.88 & & \\
\hline Gas-water & 18.56 & 18.58 & & \\
\hline
\end{tabular}




\section{Table 4}

The obtained descriptors for quercetin

\begin{tabular}{|l|l|l|l|l|l|l|}
\hline $\mathbf{E}$ & $\mathbf{S}$ & $\mathbf{A}$ & $\mathbf{B}$ & $\mathbf{V}$ & $\mathbf{L}$ & $\log K w$ \\
\hline 2.68 & 2.20 & 1.92 & 1.40 & 1.9632 & 12.33 & 18.53 \\
\hline
\end{tabular}

Our deduced solubility for quercetin in water, obtained from a 'best-fit' analysis of the data in Table 3, is $\log C w=-3.90$ at $298 \mathrm{~K}$, with units of $C w$ in mol/L. This is in the middle of the various experimental determinations, as shown in Table 1. Although solubilities in water are notoriously difficult to predict, it is useful to compare the values in Table 1, and also our suggested value, with predicted values. The EPI Suite [17] gives a predicted value of $\log C w$ from a fragmentation scheme as -3.02 and the SPARC method [18] yields a prediction of -4.81 so that our estimated value is again somewhere in the middle.

From the descriptors in Table 4, and the coefficients listed in Table 2, it is possible to predict values of $\log P s$ in the various water-ethanol mixtures, and then from $\log C w=-3.90$ to predict the corresponding solubilities as log Cs. In Fig. 1 we compare predicted and observed [2] solubilities in water-ethanol mixtures, and also our fitted value of $\log C w$ with the experimental values in Table 1. As might be expected, our predicted solubilities in the water-ethanol system are in good agreement with the experimental solubilities [2] at large vol \% ethanol, but diverge considerably as the proportion of water increases. Our suggested value for $\log \mathrm{Cw}$ is about in the mid-range of the various recorded solubilities in water.

Our conclusion is that an indirect method for estimation of aqueous solubilities leads to a solubility for quercetin in water at $298 \mathrm{~K}$ of $\log C w=-3.90$ with units of mol/L. This estimated solubility is in the middle of the range of solubilities that have been experimentally determined. 


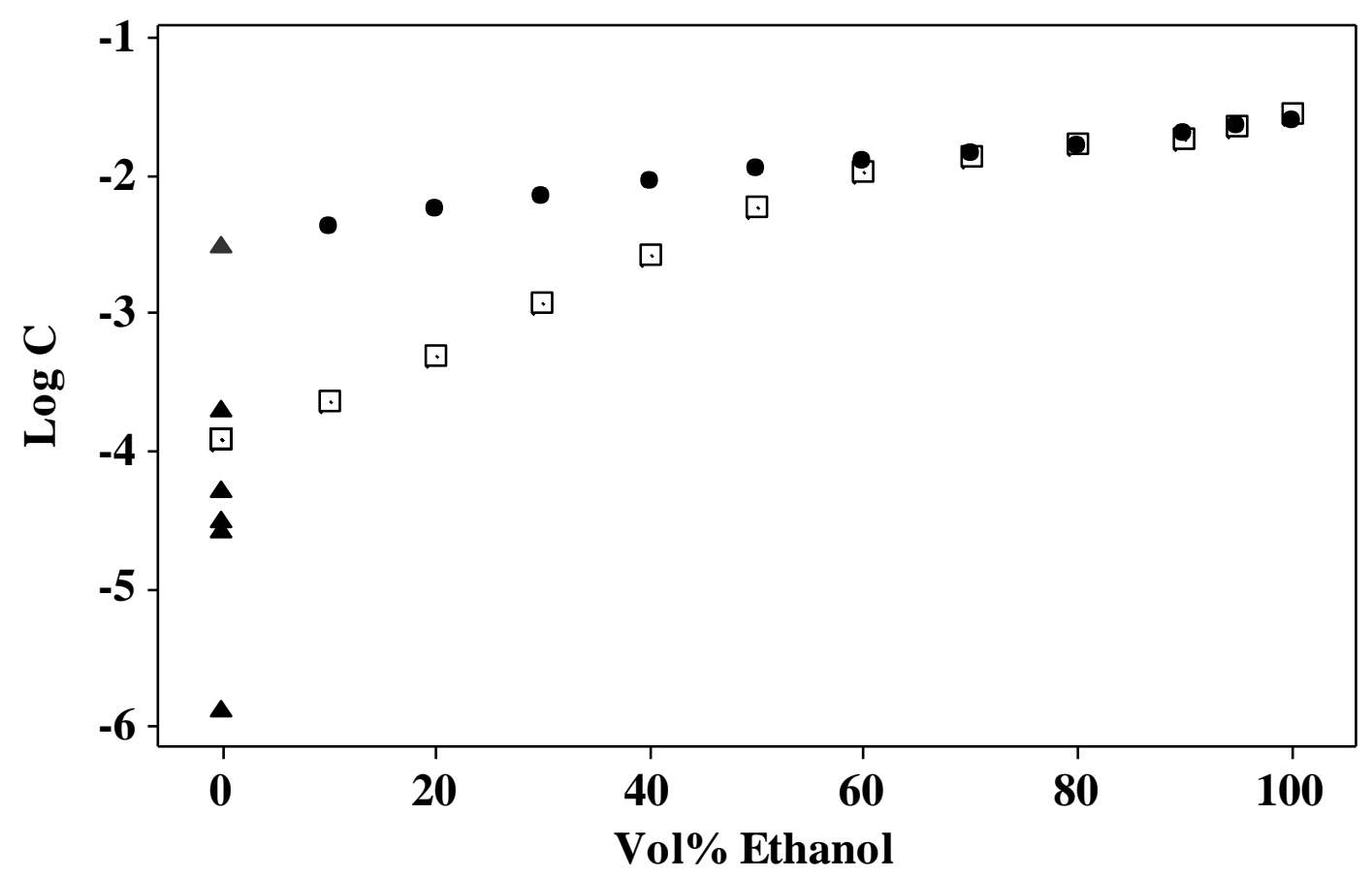

Fig. 1. Solubilities of quercetin. • Experimental values in water-ethanol solvents [2], experimental values in water from Table 1, $\square$ predicted values in water-ethanol solvents and a fitted value in water itself.

\section{References}

[1] D. Althans, P. Schrader, S. Enders, J. Mol. Liq. (2014); http://dx.doi.org/10/1016/j.molliq.2014.03.028

[2] R. S. Razmara, A. Daneshfar, R. Sahraei, J. Chem. Eng. Data, 55 (2010) 3934-3936.

[3] U.S. National Library of Medicine, November 29, 2009.

[4] M. K. Kim, K. S. Park, W. S. Yeo, H. Choo, Y. Chong, Bioorg. Med. Chem. 17 (2009) 1164-1171

[5] L. Chebil, C. Chipot, F. Archamboult, C. Humeau, J. M. Engasser, M. Ghoul, F. Dehez, J Phys. Chem. B, 114 (2010) 12308-12313.

[6] M. R. Lauro, M. L. Torre, L. Maggi, F. De. Simone, U. Conte, R. P. Aquino, Drug. Dev. Ind. Pharm, 28 (2002) 371-376.

[7] M. H. Abraham, Chem. Soc. Revs., 22 (1993) 73-83.

[8] M. H. Abraham, A. Ibrahim, A. M. Zissimos, J. Chromatogr.A, 1037 (2004) 29-47. 
[9] M. H. Abraham, R.E. Smith, R. Luchtefeld, A. J. Boorem, R. Luo, W. E. Acree, Jr, J. Pharm. Sci. 99 (2010) 1500-1515.

[10] C. F. Poole, T. C. Ariyasena, N. Lenca, J. Chromatogr. A., 1317 (2013) 85-104.

[11] E. D. Clarke, L. Mallon, “The Determination of Abraham descriptors and their Application to Crop Protection Research", in Modern Methods in Crop Protection Research, Ed. P. Jeschke, W. Krämer, U. Schirmer, M. Witschel, Wiley-VCH Verlag GmbH \& Co., 2012.

[12] Advanced Chemistry Development, 110 Yonge Street, $14^{\text {th }}$ Floor, Toronto, Ontario, M5C 1T4, Canada.

[13] ADME Suite 5.3, 2013, Advanced Chemistry Development, 110 Yonge Street, $14^{\text {th }}$ Floor, Toronto, Ontario, M5C 1T4, Canada.

[14] W. L. Whaley, E. M. Okoso-amaa, C. L. Womack, A. Vladimirova, L. B. Rogers, M. J. Risher and M. H. Abraham, Nat. Product Commun. 8 (2013) 85-98.

[15] M.H. Abraham, R. J. Abraham, J. Byrne, L. Griffiths, J. Org. Chem., 71 (2006) 3389-3394.

[16] BioLoom, BioByte Corp, 201 W. $4^{\text {th }}$ Street, \#204 Claremont, CA 91711-4707, USA.

[17] EPI suite version 4.11, www.epa.gov/opptintr/exposure/pubs/episuite/htm 2012.

[18] SPARC: http://ibmlc2.chem.uga.edu/sparc/ 